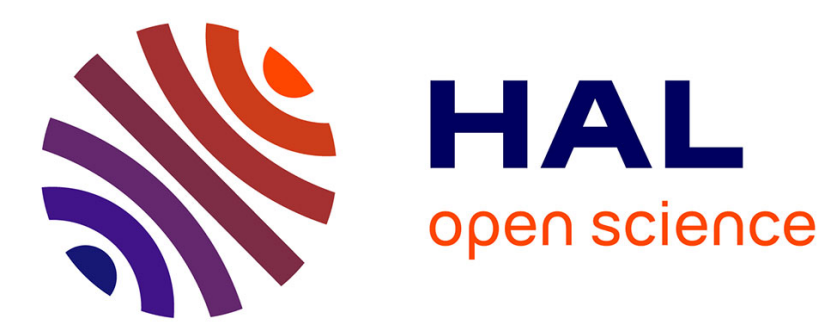

\title{
PRINCIPLE OF CONSTITUTION OF SURFACE ALLOYS UNDER LASER BEAM
}

\author{
A. Hugon, A. Galerie, M. Pons, L. Bonnetain
}

\section{To cite this version:}

A. Hugon, A. Galerie, M. Pons, L. Bonnetain. PRINCIPLE OF CONSTITUTION OF SURFACE ALLOYS UNDER LASER BEAM. Journal de Physique Colloques, 1987, 48 (C7), pp.C7-151-C7-158. 10.1051/jphyscol:1987727 . jpa-00227029

\section{HAL Id: jpa-00227029 https://hal.science/jpa-00227029}

Submitted on 1 Jan 1987

HAL is a multi-disciplinary open access archive for the deposit and dissemination of scientific research documents, whether they are published or not. The documents may come from teaching and research institutions in France or abroad, or from public or private research centers.
L'archive ouverte pluridisciplinaire HAL, est destinée au dépôt et à la diffusion de documents scientifiques de niveau recherche, publiés ou non, émanant des établissements d'enseignement et de recherche français ou étrangers, des laboratoires publics ou privés. 
PRINCIPLE OF CONSTITUTION OF SURFACE ALLOYS UNDER LASER BEAM

\author{
A. HUGON, A. GALERIE, M. PONS and L. BONNETAIN \\ Laboratoire Science des Surfaces et Matériaux Carbonés, Ecole \\ Nationale Superieure d'Electrochimie et d'Electrométallurgie. \\ INPG, CNRS UA-413, BP 75, F-38402 Saint-Martin-d'Hères Cedex, \\ France
}

\begin{abstract}
After a qualitative description of the rules of formation of laser surface alloys performed by superficial melting of both the predeposited coating and the substrate, numerical and semi-quantitative models rapidly allowing a rationnal choice of the operating conditions are presented. These models have been compared with experimental results. They give the general trends of the heat and mass transfers processes during laser alloying.
\end{abstract}

\title{
I-INTRODUCTION
}

Laser beams are able to modify metallic surfaces in a variety of ways. Consequently, they can be used for heat treatment or surface alloying when surface properties different from the bulk must be obtained (corrosion resistance, wear resistance...).

Two major classes of laser surface treatments can be performed, (i) treatments without melting generally used to achieve superficial hardening [1], (ii) treatments with melting used to modify the superficial composition (homogeneisation), the cristallinity (amorphisation) of alloys [2-8] or to incorporate foreign elements into the substrate [9-20].

This last class of laser surface treatments is still in the laboratory stage; it seems however that powder injection into the melt pool [1,21-25] would take a place in industrial processes because the laser tool offers many advantages compared with other surface treatments, in particular, the possibility of processing only chosen regions of the piece.

Our aim, in this paper, is to correlate the variables of the physical processes leading to surface alloys and the working and material parameters. Indeed, to control the process, an experimenter is faced with a multidimensional problem [26]. From the basic laws of the physical processes involved, it is possible to establish models and to compare them to well chosen experimental results in order to reach a systematization of the laser process.

\section{II-QUALITATIVE DESCRIPTION OF THE FORMATION OF LASER SURFACE ALLOYS}

The result of a laser irradiation depends on numerous parameters which may be placed in two files, (i) those characterizing the laser, (ii) those depending on the material to be treated. We shall only talk about continuous wave lasers which are generally used in metallurgy. The first file represents the working parameters which are, the laser power, the beam diameter and the scan rate of the sample. The second file encloses the physical properties of the coating and of the substrate in the solid and liquid states. All the physical quantities used are listed at the end of this paper with their definition and their dimerision.

When the radiation strikes the coating-substrate system, the heat produced in a very thin superficial layer may lead to the melting. At this instant, the melting of the coating begins at the coating-air interface; the melting interface moves through the 
material because of the thermal conduction and of the convection in the liquid phase. When the melting interface reaches the coating-substrate interface several possibilities arise; (i) if the melting point of the substrate is much higher than that of the coating, an overheating of the liquid coating will be necessary to reach the melting point of the substrate; (ii) if the melting point of the substrate is smaller than that of the coating, the melting interface will go away from the coating-substrate interface; when the coating and the substrate are both liquid, the high convection rates lead to a vigourous mixing, allowing the formation of a surface alloy. It is generally shown that the driven force of the convection is the surface tension gradient which is due to the temperature (or concentration) difference between the center and the edges of the melt pool leading to a motion of the liquid from the high (center) to the low temperatures (edges). The complete study of this matter motion leads to take in account the surface tension forces; this phenomenon involve convection rates one or two order magnitude greater than the scan rate of the laser [27-33].

A model giving a complete description of the process would take into account, the irradiation parameter $(\mathrm{q}, \mathrm{d}, \mathrm{V})$, the physical properties of the materials $(\sigma, \mathrm{k}, \mu, \mathrm{Tf}, \mathrm{H}, \alpha)$ and the heat and mass transfers in the multiphase flow. At the present time, a complete model does not exist, but some good attempts have been made [27-33]. From lack to give a full description, we have chosen to present different models with progressive complications, each model bringing, without too much complexity, partial informations (sometimes enough for the aimed applications).

In the section III, we present a simple model taking only into account the conduction heat transfer and the phase changes. This model, neglecting the convection, may be justified for metals. Indeed, the work of Srinivasan and al. [30] has shown that, for the materials which have a Prandtl number lower than 0.1 (case of metals), the convection very slightly modifies the heat transfer in the melt pool.

In the section IV, we propose a semi-quantitative model taking into account more parameters (convection parameters). This study will allow to point out the driven forces of the convection and to give some trends of the mechanism of alloying.

\section{III-CONDUCTION MODEL}

\section{$\underline{\text { III- } 1 \text { NUMERICAL RESULTS }}$}

The numerical results obtained from a conduction model with moving boundaries (solid-liquid interface) have allowed us to study, for a given coating-substrate system the influence of the working parameters $(q, d, v)$ and the influence of the nature and of the thickness of the coating.

From figures 1 and 2 we can note that, (i) for long interaction times (i.e. small scan rates) the temperature reaches a stationnary value, (ii) several couples ( $q, \tau$ or $v$ ) are possible to obtain the same result. It is in fact the law q $\sqrt{t}=$ constant which allows to determine the couplage when the stationnary state is not reached.

From a practical point of view, a good compromise between power and scan rate will allow to reach the wished result without using prohibitive power or scan rate. This model rapidly allows this choice to be made.

The nature and the thickness of the coating also greatly influence the heat transfer. The model can easily give the general trends; a more detailled description of these results is given in another paper [34].

\section{III-2 CONCLUSIONS}

This simple model allows to establish the working conditions to reach the melting. Melting must be necessary reached to obtain alloying but it is not sufficient to predict the formation of a surface alloy. Indeed, this model gives no information about the mixing of the liquid materials governed by the physical quantities of the flow. A good correlation was however found between numerical and experimental results for pure metals and some binary systems (Fe-Ni, Fe-Al..) [26,35]. 


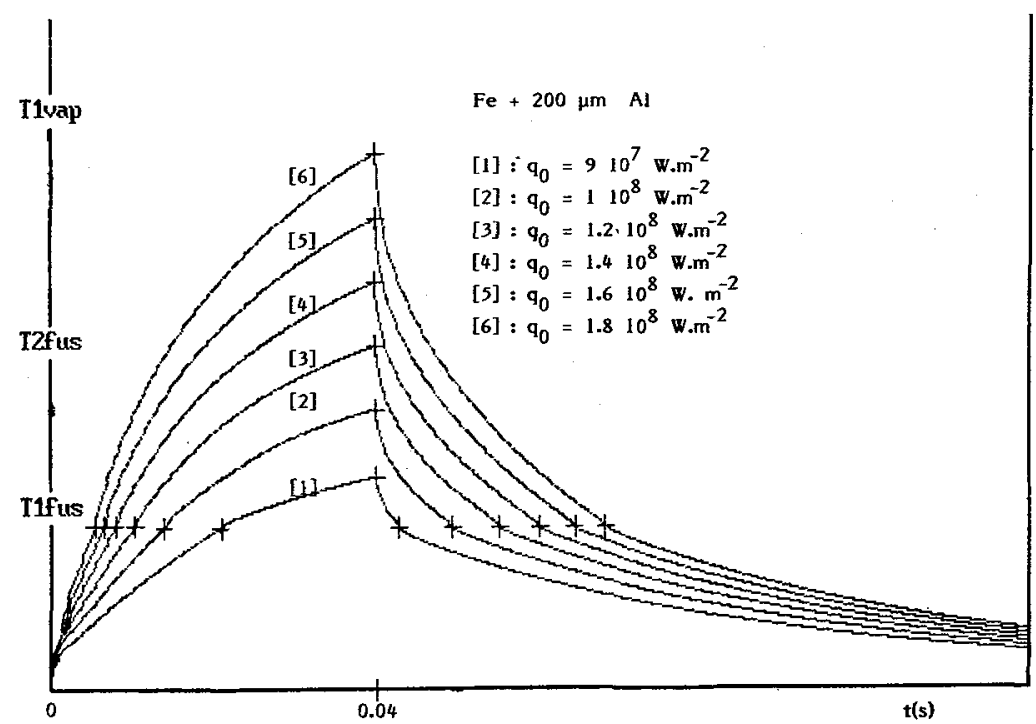

Figure 1: Thermal evolution of the surface of mild steel coated with $200 \mu \mathrm{m}$ of aluminium for different values of absorbed power density and for a fixed value of the scan rate $(\mathrm{V}=1 \mathrm{~cm} / \mathrm{s}) ; \mathrm{T} 1$ fus $=660^{\circ} \mathrm{C} ; \mathrm{T} 2 \mathrm{fus}=1535^{\circ} \mathrm{C}$.

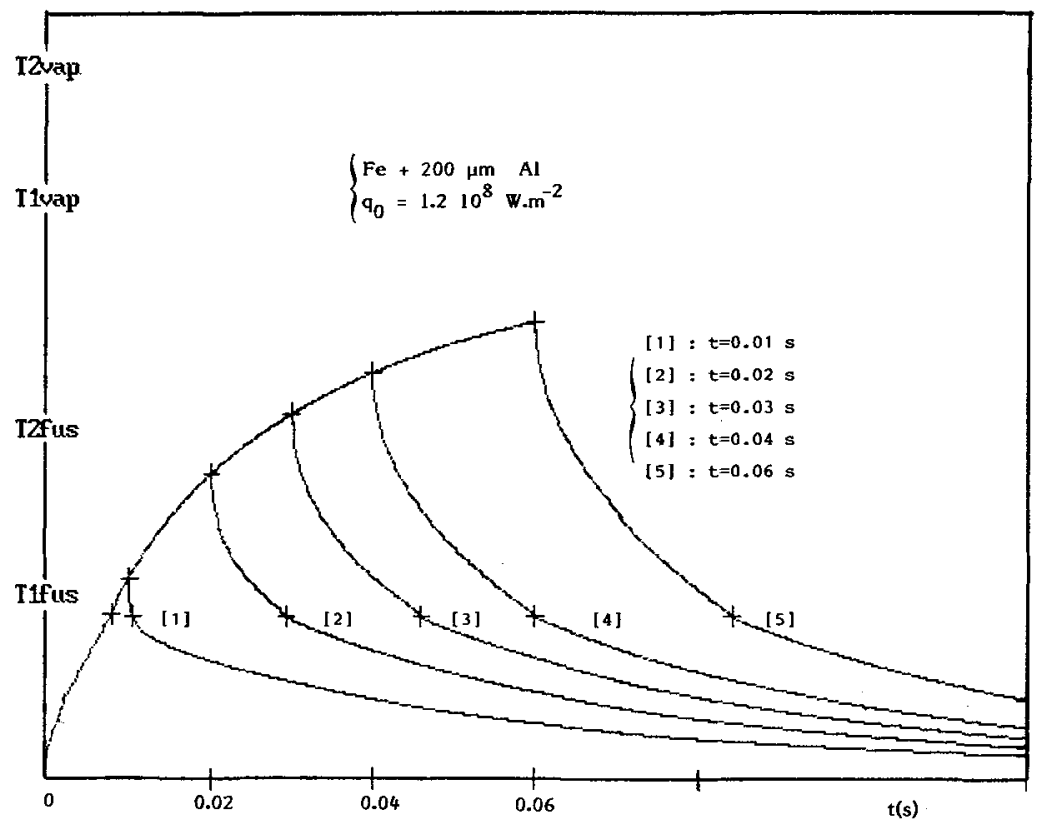

Figure 2: Thermal evolution of the surface of mild steel coated with $200 \mu \mathrm{m}$ of aluminium for different values of scan rate and for a fixed value of the absorbed power density; T 1 fus $=660^{\circ} \mathrm{C}$; T2fus $=1535^{\circ} \mathrm{C}$. 


\section{IV-THE CONVECTION}

In the section dealing with the processes of formation of laser surface alloys, we have pointed out that the convection motion may be due to the difference of temperature between the center and the edges of the melt pool leading to a force (depending on the surface tension gradient) which drives the liquid from the center to the edges of the pool. The problem that we have to solve is to know if this force is the only driving force for convection and what are the modifications to be done to the conduction model to take it into account.

\section{IV-1 NATURAL GRAVITATIONAL OR INTERFACIAL CONVECTION}

The natural convection within a fluid is, by definition, due to physical quantities gradients which involve forces, eventually binded to pressure forces; (the forced convection being due to pressure forces directly applied).

The most known natural convection within a fluid arises from volumic weight gradients; these gradients are due to temperature or/and concentration inhomogeneities; this kind of natural convection would be called gravitational natural convection (thermal or of concentration).

Recently, in materials processing under microgravity conditions, the influence of interfacial quantities (surface tension gradients) was shown to be of importance in convection mechanism [36].

We are going to discuss, from a simplified model, the respective influences of the different acting forces. Our aim is to deduce the preponderance regions of these two kinds of convection. In the first part of the discussion, only temperature gradients will be taked into account.

The convective flow is studied in a rectangular cavity (figure 3). This geometry may be an approximation of a melt pool. Three forces take place in the cavity, (i) the viscous stress forces $(\mathrm{F} \mu)$ which slow the motion, (ii) the buoyancy forces $(\mathrm{Fg})$ which depend on the thermal gradients in the whole volume, (iii) the surface tension forces $\left(\mathrm{F}_{\boldsymbol{\sigma}}\right)$ which depend on the surface thermal gradient.

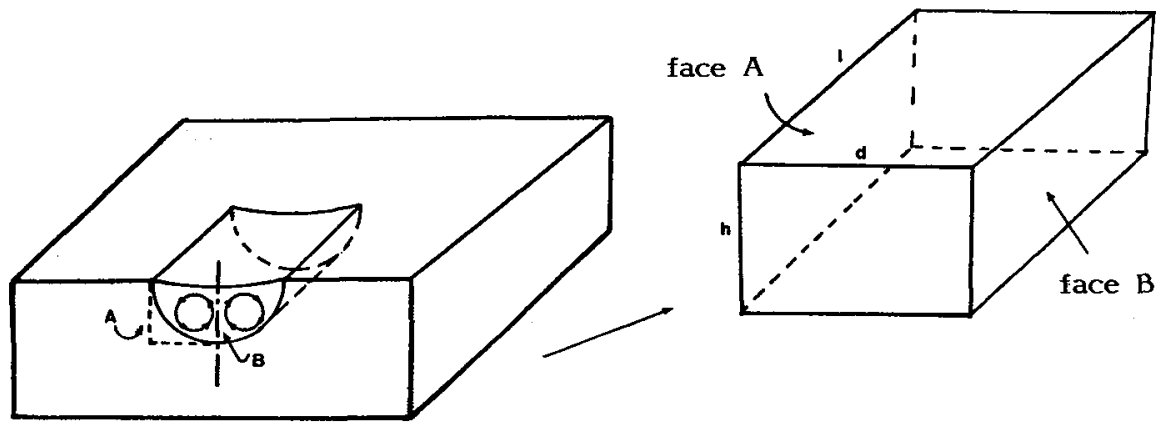

Figure 3 : Approximation of the melt pool by a cavity

These forces can be expressed [34]:

$\mathrm{F} \mu=\mu \mathrm{uhl} / \mathrm{d}$

$$
\begin{aligned}
& \mathrm{Fg}=g \beta \rho\left(\mathrm{T}_{\mathrm{A}}-\mathrm{T}_{\mathrm{B}}\right) \mathrm{h}^{2} \mathrm{l} \\
& \mathrm{F}_{\sigma}=(\mathrm{d} \sigma / \mathrm{dT})\left(\mathrm{T}_{\mathrm{A}}-\mathrm{T}_{\mathrm{B}}\right) \mathrm{l}
\end{aligned}
$$

The dimensionless number characterizing the natural convection depending on density gradients $(\rho)$ due to temperature or/and composition gradients is the Grashof number $(\mathrm{Gr})$. It expresses the comparative importance of gravitational forces $(\mathrm{Fg})$ and viscous forces $(F \mu): F g / F \mu=G r / \operatorname{Re}$ ( $R e$ is the Reynolds number). 
The dimensionless number characterizing the interfacial convection is the Marangoni number $(\mathrm{Mr})$ or the Reynolds-Marangoni number $(\mathrm{R} \sigma)$. They express the competition between the surface tension forces $\left(\mathrm{F}_{\sigma}\right)$ and the viscous forces $(\mathrm{F} \mu): \mathrm{F}_{\sigma} / \mathrm{F} \mu=\mathrm{R}_{\sigma} /(\mathrm{A} . \mathrm{Re})$

The different dimensionless numbers, $A, R e, G r, \operatorname{Pr}, R_{\sigma}, M r$ are defined in table 1 .

\begin{tabular}{|ll|}
\hline Äspect ratio & $\mathrm{A}=\mathrm{h} / \mathrm{d}$ \\
\hline Reynols number & $\mathrm{Re}=\mathrm{ud} / \nu$ \\
\hline Prandtl number & $\mathrm{Pr}=\nu / \alpha$ \\
\hline Grashoff number & $\mathrm{Gr}=\mathrm{g} \beta \Delta \mathrm{Td}{ }^{2} \mathrm{~h} / \nu^{2}$ \\
\hline Reynolds-Marangoni number & $\mathrm{R} \sigma=\sigma^{2} \Delta \mathrm{Td} / \rho \nu^{2-}$ \\
\hline Marangoni number & $\mathrm{Mr}=\mathrm{R}_{\sigma} \cdot \mathrm{Pr}$ \\
\hline
\end{tabular}

Table 1: definitions of the dimensionless numbers (for a temperature gradient $\Delta \mathrm{T}$ )

The ratio between the gravitational forces and the surface tension forces allows to determine the comparative importance of the two kinds of convection described above:

$\mathrm{Fg} / \mathrm{F} \sigma=(\mathrm{Gr} . \mathrm{A}) / \mathrm{R}_{\sigma}$

From this description of the driven forces of the fluid flow in a cavity, we can conclude that the comparative influence of the two kinds of convection will depend on the quantity $(\mathrm{Gr} . \mathrm{A}) / \mathrm{R}_{\sigma}$. The aspect ratio (A) involves a two-dimentionnal criterion.

This study is in fact very simplified. A more detailed study would allow us to give a better criterion; instead of the quantity $A$, it would be necessary to make appear a function of $A$, which can be zero when $A$ tends to zero, the gravitational forces being very weak comparatively to the interfacial forces.

\section{IV-2 APPLICATION TO LASER MELTING}

Generally, for laser melting, it can be considered that the melt depth (h) may vary from $0.1 d$ to $d$ ( $d$ is the width of the melt pool). The aspect ratio A may then vary from 0.1 to 1 . The calculated values of $\mathrm{Gr} / \mathrm{R} \sigma$ and (Gr.A)/R $\sigma$ are small [34]. The temperature gradient between the center and the edges of the melt pool is generally about 500 $\mathrm{K} . \mathrm{mm}^{-1}$. The width of the melt pool is considered to be equal to the beam diameter $(\mathrm{d}=1 \mathrm{~mm})$.

It is therefore difficult to fix a limit for the ratio $\mathrm{Gr} / \mathrm{R} \sigma$ or $(\mathrm{Gr} . \mathrm{A}) / \mathrm{R} \sigma$ as in the monodimentionnal approximation of Favier and al. [37]. In laser melting processing $(0.1 \leq A \leq 1)$, it can be noted that these two ratios are small and thus, we can conclude that the convection would be essentially due to the surface tension gradients.

It is therefore important to note that we have only studied pure metals subject to thermal gradients. Actually, the volumic weight and surface tension depend as well on temperature as on composition, so:

$$
\frac{\partial \sigma}{\partial \mathbf{x}}=\frac{\partial \sigma}{\partial \mathrm{T}} \frac{\partial \mathrm{T}}{\partial \mathrm{x}}+\frac{\partial \sigma}{\partial \mathrm{C}} \frac{\partial_{\mathrm{C}}}{\partial \mathrm{x}}
$$

and at the surface :

$$
\mu-\frac{\partial u}{\partial y}=\frac{\partial \sigma}{\partial x}
$$

For alloys containing tensioactive elements, the magnitude of the Reynolds Marangoni number $\left(R_{\sigma}\right)$ can be drastically modified. The interfacial convection due to a thermal gradient would be negligible and the motion of the melt would then be due to gravitational convection or to interfacial convection due to a concentration gradient. 


\section{IV-3 CONCLUSION}

We have shown that, in the laser melt pools which have generally an aspect ratio lower than 1, the driven forces of the convection are the surface tension forces arising from temperature gradients. This is true when, (i) the melt composition is uniform, (ii) the surface does not contain tensioactive elements.

During the formation of laser surface alloys by simultaneous mixing of a predeposited coating and of the substrate, the mixing is mainly due to convection motion. The surface tension gradients arising from temperature and composition differences take place during the homogeneisation of the pool. So, it is necessary to take in account the surface tension gradient $(\partial \sigma / \partial x)$. The values of $(\mathrm{Gr} . \mathrm{A}) / \mathrm{R}_{\sigma}$ or $\mathrm{Gr} / \mathrm{R}_{O}$ allow to determine initially the vigor of the fluid flow and so to predict the feasibility of a surface alloy.

\section{V- CONCLUSIONS}

The different models presented allow to give partial informations sometimes sufficient for the aimed applications.

In the first model (rigid model) we have shown the influence of the working parameter; general trends have been derived from thermal parameters easily available.

In the second model, taking in account the convective motion, we have shown that the driven forces of the convection are the surface tension forces; the values of the ratio (Gr.A)/R $\sigma$ which express the relative importance of the buoyancy and interfacial forces give informations about the vigor of the fluid flow and so on the homogeneity of the resulting surface alloy.

\section{LIST OF SYMBOLS}

\begin{tabular}{|c|c|c|c|}
\hline \multicolumn{4}{|l|}{ laser beam diameter } \\
\hline$h$ thickness of the & & $\rho$ density & {$\left[\mathrm{ML}^{-3}\right]$} \\
\hline melt pool & {$[\mathrm{L}]$} & $\alpha$ thermal diffusivity & {$\left[\mathrm{L}^{2} \mathrm{~T}^{-1}\right]$} \\
\hline $\mathbf{k}$ thermal conductivity & {$\left[\mathrm{MLT}^{-3}-1\right]$} & $\nu$ kinematic viscosity & {$\left[\mathrm{L}^{2} \mathrm{~T}^{-1}\right]$} \\
\hline$P$ laser power & {$\left[\mathrm{ML}^{2} \mathrm{~T}^{-3}\right]$} & $\mu$ viscosity & {$\left[M T^{-1} L^{-1}\right]$} \\
\hline$q$ power density & {$\left[\mathrm{MT}^{-3}\right]$} & $\sigma^{\prime}$ surface tension & \\
\hline $\mathrm{q}_{0}$ absorbed power density & {$\left[\mathrm{MT}^{-3}\right]$} & gradient & {$\left[M T^{-2} \theta^{-1}\right]$} \\
\hline $\mathrm{R}$ reflectivity & dimentionless & $\tau$ interaction time & {$[\mathrm{T}]$} \\
\hline$\Upsilon$ temperature & {$[\theta]$} & & \\
\hline $\begin{array}{l}\text { u-component of the } \\
\text { fluid velocity }\end{array}$ & {$\left[\mathrm{LT}^{-1}\right]$} & & \\
\hline$v$ y-component of the & & & \\
\hline fluid velocity & {$\left[\mathrm{LT}^{-1}\right]$} & & \\
\hline$V$ scan rate & {$\left[L T^{-1}\right]$} & & \\
\hline
\end{tabular}




\section{REFERENCES}

[1] G. CoQuerelle, M. Colin, J.L. FACHINETTI, Trait. Therm., 202 (1986) 51

[2] E. Mc CAFFERTY, P.G. MOORE, G.T. PEACE, J. Electrochem. Soc., 129 (9) (1982) 9

[3] A.B. VANNES, C. CHABROL, J. HERNANDEZ, Trait. Therm., 202 (1986) 27

[4] P.A. MOLIAN, W.E. WOOD, J. Mater. SCi., 18 (1985) 2555

[5] P.T. COTRELL, R.P. FRANKENTHAL, G.W. KAMLOTT, D.J. SICONOLFI, C.W. DRAYER, J. Electrochem. Soc., 130 (5) (1983) 998

[6] C. Christodoulou, A. WALKER, W. M. STEEN, D.R.F. WeST, Met. Technol., $10(1983) 215$

[7] J.G. SMEGGIL, A.W FUNKENBUSH, N.S. BORNSTEIN, High Temp. Sci., $\underline{20}(1985) 163$

[8] H.W. BERGMANN, B.L. MORDIKE, Z. Werkstofftechn., 14 (1983) 228

[9] T.R. TUCKER, A.H. CLAUER, S.L. REAM, C.T. WALTERS, in B.H. Kear, B.G. Giessen, M. Cohen (eds), Rapidly Solidified Amorphous and Crystalline Alloys Elsevier, Amsterdam, 1983, p. 541

[10] P.J. MOORE, E. MC CAFFERTY, in E. Mc Cafferty, C.R. Clayton, J. Oudar (eds), Fundamentals Aspects of Corrosion Protection by Surface Modification, The Electrochemical Society, Pennington, NJ, 1983, p. 112

[11] M. PONS, M. CAIllet, A. GALERIE, J. Mater. Sci., 21 (1986) 2697

[12] S. DAS, I. DUMBER, J. MAZUMDER, in M.F. Kimmit (ed), Lasers in Manufactering, North Holland, Amsterdam and IFS, Bedford, 1985, p. 127

[13] T. CHANDE, J. MAZUMDER, dans E.A. Metzbower (ed), Lasers in Material Processing, American Society for Metals, Metal Park, OH, 1983, p. 127

[14] G. CHRISTOdOULOU, W.M. STEEN in E.A. Metzbower (ed), Lasers in Material Processing, American Society for Metals, Metal Park, OH, 1983, p. 116

[15] R. STREIFF, M. CAILLET, P. MAZARS, in Société de Chimie Industrielle et Centre Français de la Corrosion (eds), Proc. 8th European Congress of Corrosion, Nice, France, 19-21 Nov 1985, 1985, Vol 1, p. 64

[16] C. A. LIU, M. J. HUMPHRIES, C.R. KRUTENAT, Thin Solid Films, 107 (1983) 269

[17] D.S. GANNAMUTHU, Opt. Eng., 19 (9) (1980) 783

[18] R.J. PANGBORN, D.R. BEAMAN, J. Appl. Phys., 51 (1) (1980) 5992

[19] M.L. CAPP, J.M. RIGSBIE, Mater. Sci. Eng., 62 (1984) 49

[20] P.A. MOLIAN, W.E. WOOD, Mater. Sci. Eng., 62 (1984) 271

[21] T. TAKEDA, W.M. STEEN, D.R.F WEST, dans M.F. Kimmit (ed), Lasers in Manufactering, North Holland, Amsterdam et IFS, Bedford, 1985, p. 85

[22] W.M. WEERASINGHE, W.M STEEN, Weld. Met. Fab., (1983) 3

[23] 3.D. AYERS, Thin Solid Films, 84 (1981) 223

[24] J.D. AYERS, R.S. SCHAEFER, W.P ROBEY, J. Met., 8 (1981) 19

[25] W.M. WEERASINGHE, W.M. STEEN, in M.F. Kimmit (ed), Lasers in Manufactering, North Holland, Amsterdam et IFS, Bedford, 1983, p. 125

[26] A. GAleRIE, M. PONS, M. CAIllet, Mater. Sci. Eng., 88 (1987) 127 
[27] P.R. STRUTT, J. Le MAY, A. TAUQUIR, Mat. Res. Soc. Symp. Proc., Vol. 28, Elsevier, NY, 1984, p. 87

[28] T.R. ANTHONY, H.E. Cline, J. Appl. Phys., 48 (9) (1977) 3888

[29] C. CHAN, J. MAZUMDER, M.M. CHEN, Met. Trans., 15A (1984) 2175

[30] J. SRINIVASAN, B. BASU, Int. J. Heat Mass Transf., 29 (4) (1986) 563

[31] T. CHANDE, J. MAZUMDER, Appl. Phys. Lett., 41 (1) (1982) 42

[32] C.R. HEIPLE, J.R. ROPER, R.T. STAGNER, R.J. ADEN, Weld. Res. Suppl., March 1983, 72s-77s

[33] S.M. COPLEY, D. BECK, O. ESQUIVEL, M. BASS, in S.D. Ferris, H.J. Leamy J.M. Poate (eds), Laser Solid Interactions and Laser Processing, AIP Conf. Proc. 50, American Institute of Physics, NY, 1979, p. 161

[34] M. PONS, A. GALERIE, P. WITOMSKI, L BONNETAIN to be published in Ann. Chim. Fr.

[35] A. GAlerie, A. HUGON, M. PONS, to be published in High Temp. High Press.

[36] S. OSTRACH, Annual Rev. Fuid. Mech., 14 (1982) 313

[37] D. CAMEL, P. TISON, J.J. FAVIER, Proc. 36th Congress of the International Astronautical Federation, Stockholm, Suède, 7-12 Oct. 1985, Pergamon Press, 1985, p. 1 